\title{
The five resources of critical digital literacy: a framework for curriculum integration
}

\author{
Juliet Hinrichsen* and Antony Coombs \\ Educational Development Unit, University of Greenwich, London, UK
}

(Received 7 May 2013; final version received 29 October 2013)

\begin{abstract}
This article sets out a framework for a critical digital literacy curriculum derived from the four resources, or reader roles, model of critical literacy developed by Luke and Freebody (1990). We suggest that specific problematics in academic engagement with and curriculum development for digital literacy have occurred through an overly technocratic and acritical framing and that this situation calls for a critical perspective, drawing on theories and pedagogies from critical literacy and media education. The article explores the consonance and dissonance between the forms, scope and requirements of traditional print/media and the current digital environment, emphasising the knowledge and operational dimensions that inform literacy in digital contexts. It offers a re-interpretation of the four resources framed as critical digital literacy (Decoding, Meaning Making, Using and Analysing) and elaborates the model further with a fifth resource (Persona). The article concludes by identifying implications for institutional practice.
\end{abstract}

Keywords: curriculum development; academic development; digital identity

\section{Introduction}

In considering an approach to curriculum integration of digital literacy, we were conscious of a number of problematics, contexts and contradictions. The problematics included the need to define digital literacy sufficiently to implement it institutionally. Defining in this case goes beyond the trivial task of finding a form of wording but rather involves identifying an ideological position within the contested discourses of technology. The contexts included known issues with staff engagement, an overburdened curriculum, shortage of resources and variability in student (digital) profile. The contradictions centred on the need to address outcome-oriented approaches which could impact on attainment, employability and graduate profile, whilst avoiding the limitations of a taxonomic approach in terms of tools, technologies and skills; limitations such as rapid changes in technology, variability in perception of what is considered essential content and particularities of institutional infrastructure. There was also a reluctance to be technology led in our thinking about curriculum and student learning. Drawing on approaches from literacy education enabled us to resolve these contradictions and reconcile practical requirements, whilst addressing deeper epistemological stances that have structural and operational implications.

*Corresponding author. Email: j.hinrichsen@gre.ac.uk 


\section{Defining digital literacy: positions}

Analyses of the terms used in the arena of digital literacy and its associated terms (see Goodfellow 2011), including media literacy/cies (Buckingham 2006; Livingstone 2004); digital scholarship (Pearce et al. 2010); new literacy studies and multiliteracies (Street 2003) and multiple technoliteracies (Kahn and Kellner 2005) reveal complexity, variation and disputation. Across these different positions it is possible to identify a consistent tension between perceptions of technology as either neutral or culturally situated, along with the implications each view has for policy, practice and curriculum. This debate has a long history and has centred on the oppositional axis of technological and social determinism [also dominant and antidominant discourse (Barton 1994)]. Technological determinism is generally an implicit position, typified by conceptions of technological neutrality (a tool paradigm, open to positive or negative uses), autonomous advancement (we must adapt 'because it is here'; the dangers of being 'left behind') or proselytising (universally positive impacts; polarising constructions such as 'dinosaurs' or 'luddites'). Social determinists have argued that technology is shaped by political, economic and socio-cultural factors, reflects these purposes, influences and meanings and thus is never neutral (Beynon and Mackay 1992; Glastonbury and LaMendola 1992; Haddon 1991; Mackay, Young, and Beynon 1991; Mackenzie and Wajcman 1985; Selfe and Hilligoss 1994). By deconstructing or 'reading' technology such influences and meanings can be made more explicit; for example, the gendering of technology (Cockburn 1985, 1991; Wahlstrom 1994), surveillance (Lyon 1994) or consumption (Haddon 1991). This mirrors oppositions in literacy studies between functional and critical perspectives, or autonomous and ideological positions (Street 2003). Understanding such underlying positions, or assumptions, allows researchers and practitioners to be explicit about their position and reflective of its consequences. For example, the way one might address digital literacy in professional development or developing graduateness is coloured by the meanings associated with these stances.

Whilst it is accepted that there is iteration and interaction between culture and technology, arguably a more deterministic or functional perspective has remained dominant at policy and institutional levels (Kahn and Kellner 2005; Lea 2013; Lea and Goodfellow 2009).

\section{Implications of functional approaches}

Such ideological tensions move beyond epistemological and disciplinary spaces when they are translated into curriculum content, delivery strategies, institutional strategies and investment. They also infuse the perceptions of academics in their engagement with digital technology.

\section{Academic engagement}

A hard skills framework of 'IT literacy' has, we believe, had a divisive effect on academics, constructing them differentially in relation to their technical skills and also in their attitudes to technology. Generational polarisation may promote a deficit model (Bayne and Ross 2007; Lea 2013) which can also militate against engagement. From a professional development angle, a technocratic or functional perspective puts emphasis on the academic role as a conduit to student skill rather than on personal, 
professional or disciplinary development. The JISC, sponsors of the national UK Developing Digital Literacies Programme, also calls for professional development to:

focus less on the adoption of specific new technologies and more on how meaningful tasks which explore authentic academic digital practices can be embedded in curriculum learning and how emerging digital practices might be usefully recontextualised in an academic setting. (Payton 2012, p. 2)

Such an approach has clear implications for staff development initiatives and invites co-curricula approaches between educational developers, learning technologists and academics. However, we suggest that it requires a reframing of the notion of the digital in relation to literacy.

\section{Curriculum implications}

A disembedded discourse with regard to technology has, arguably, become progressively more exposed as problematic and dislocated from the practices of academia whilst underutilising the potential to align better with the requirements of the workplace (Yorke 2006). Disengaging context and practice from use in the acquisition of practical skill (e.g. the computer lab rather than the seminar room) serves to reinforce several ideas: that competences can be developed in isolation from each other and will somehow concatenate naturally; that developing digital literacy is about operational and not intellectual activity; that the methods of enquiry and analysis embedded in application software are neutral [see for example Wahlstrom (1994) on the assumptions in spell checkers].

From a curriculum perspective, a functional framing of technology misses the opportunity for the development of a range of academic skills and practices which are not only important in their own right, but which inform effective engagement with the digital, as we shall argue.

\section{Learner profiles}

In thinking about appropriate curriculum responses to digital literacy development, the analysis of learner characteristics in relation to the digital is important. The concept of the 'digital native' (after Prensky 2001) and similar generational categorisation has received much criticism as undertheorised and deterministic (Jones 2011), divisive and disempowering (Bayne and Ross 2007) and evidence of an alarmist 'moral panic' (Bennett, Maton, and Kervin 2008). Some studies examining the digital skillsets of students have concluded that variation is significant and poorly aligned to age group (Jones et al. 2010), limited in range and highly influenced by lecturer methods (Margaryan, Littlejohn, and Vojt 2011) and there is increasing awareness of poor transfer from informal to formal learning of the skillsets that students may bring with them (Littlejohn, Beetham, and McGill 2012). Our observation is that some of the characteristics of student engagement with technology at university seem to form around a set of disassociations. In addition to the lack of transfer of skills or use of tools between spheres of practice, an example of the disassociation between students' academic and personal or social identity is highlighted in an analysis of students' Facebook photobiography (Mendelson and Papacharissi 2011). Framing Facebook as 'identity performance' and 'symbolic creation of their worlds' (pp. 251-252), these researchers found that in transitioning 
to college, students projected the personal and social dimensions of their experience whilst academic life was almost absent, even in photograph settings. Disassociation can be seen in other ways too, as the academic skills being fostered in their subjects (seeking evidence, evaluating provenance, rejecting weak arguments) are not being applied in their uses of technology as exemplified by expedient, superficial or 'satisficing' search behaviours (Kennedy and Judd 2011). In a study of high-school multi-modal text production Levy and Michael (2011, p. 95) conclude 'regardless of their technical fluency, students still require traditional skills for successful task completion' whilst Margaryan, Littlejohn, and Vojt (2011, p. 438) identify 'a deficit of learning literacies'. At the same time, there has been a proliferation of cases which have exposed the implicit dangers of naïve engagement with technology, including social media scandals (e.g. Tweed 2012), scam emails (Balamurugan et al. 2008) and reputational impact (Aula 2010) all emphasising the critical, evaluative skills required for effective professional, personal and civic engagement. The current focus on employability enhancement in the curriculum points to reputation management and identity awareness as a key site for digital literacy development. It is clear, however, that broader literacy practices are not going to emerge spontaneously as a result of technology proliferation or early exposure and that education has an important role in inculcating, moderating and extending such practices.

There is thus potential, if not an imperative, to find ways to integrate not only technology into the discipline but, perhaps more importantly, the discipline into the technology.

\section{Redressing the balance: critical digital literacy}

The shift from a machine-focused viewpoint (IT) to the more diffuse meaning implied by the term 'digital' in conjunction with literacy signals an opportunity for a corresponding shift from a skills agenda to the idea of situated practices. There are increasing calls to rebalance the emphasis on manipulative and operational skill with a focus on the practices and intellectual traditions of the disciplines (Goodfellow 2011; Lea 2013; Littlejohn, Beetham, and McGill 2012) both as meaningful sites of learning and as a reflection of a shift towards critical academic literacies.

\section{What do we mean by 'critical'?}

There are two senses of a critical dimension at play, and both are implied when we use the term. These meanings can be regarded as internal to and external to the digital. By internal we refer to faculties of analysis and judgement as applied to the content, usage and artefacts of the technology. The external meaning relates to a position regarding the development, effects and social relations bound in technology. This position is more associated with historical and cultural analyses and operates in a wider field of technology than computers. It is concerned particularly with how meaning is constructed, by whom and for what purposes and in this sense representational and communicational modes are central. Tools of enquiry from this perspective include textual practices such as semiotic and discourse analysis. The elaborated idea of a text as an organised collection of representations brings to bear the relevance of literacy practices to describe, teach and think about such meanings; overarching this are the discourses of power around technology that can further be seen as texts (Dowling 1991). The perspectives of media education (Buckingham 
2006; Livingstone 2004) are also major contributions to our understanding of a critical digital literacy.

\section{Why develop a new framework?}

This work was located in a national project on digital literacy (http://www.jisc.ac.uk/ whatwedo/programmes/elearning/developingdigitalliteracies/DLinTransition.aspx), part of which required curriculum mapping of digital literacies. However, trying to develop methods to do this repeatedly resulted in a drift towards functional approaches (what tools and what skills) and incoherent variability (disciplinaryspecific uses with no unifying concepts); nor did they address the issues of engagement, learner need and contested scope outlined previously. The perspectives of critical literacy offered a relevant approach, however required contextualisation for the digital. The critical digital literacy framework outlined below is the outcome of that work. It has been pilot tested in workshop form with a number of constituencies (academics, students, learning technologists, managers) to gauge (1) its acceptability and (2) its use in activity design. It has been positively evaluated so far (https:// sites.google.com/site/dlframework/toolsandsupport/exploringdl/workshop-evaluation). Further work is in progress to produce support resources, disciplinary exemplars and course or programme-level tools.

One of the purposes served by the framework is scoping. The importance of this scoping activity lies in its role as a conduit to shared meaning. Given the many interpretations of digital literacy, developing a common understanding of its dimensions is a prerequisite to effective institutional embedding and curriculum integration. By delineating a range of filters through which digital literacies can be examined, taught or understood, a number of perspectives and angles can be considered.

\section{The four resources model of critical literacy}

The particular model of critical literacy that has informed the development of our critical digital literacy framework is the four resources model developed by Allan Luke and Peter Freebody (Freebody and Luke 1990; Luke and Freebody 1999). This model takes a critical literacy perspective framed loosely in terms of reader 'roles' or 'resources' identified as 'families of practice' (Freebody 2002; Luke and Freebody 1999). Its focus on learner processes rather than syllabus specification made it an excellent candidate for the approach we wanted to develop. The practical provenance of the model is significant, having been both accepted and adopted on a large scale in literacy education internationally [Ludwig 2003; The Literacy and Numeracy Secretariat (Ontario Ministry of Education) 2009]. It has also proven to be a useful framework for curriculum and classroom analysis (Honan 2008) and developing learner metacognition (Henderson and Hirst 2007; Hirst et al. 2004). Although these initiatives come from the schools sector we believe that this model is relevant to higher education in its articulation of the basis for critical analysis and its operational adaptability in classroom settings.

The four resources, or reader roles, are code breaking, text-participating, text using and text analysing. A useful overview of these roles is provided by Ludwig (2000, pp. 1-2, in Hirst et al. 2004). 
Successful literacy learners [...] need to engage in all four roles and be

- code breakers - How do I crack this text? How does it work?

- text participants or meaning makers - How do the ideas represented in the text string together? What are the cultural meanings and possible readings that can be constructed from this text?

- text users - How do the users of this text shape its composition? What do I do with this text, here and now?

- text analysts - What is this text trying to do to me? In whose interests?

Whilst this model focuses on reader roles, the context of the digital also places emphasis on authorial elements. Levy and Michael (2011) conclude from their analysis of multi-modal text production by Australian high-school students that not only does production provide opportunities to develop and apply skills and knowledge but also has great potential to enhance knowledge construction. Thus a constructive emphasis on creating, shaping, adapting and co-creating texts is also implied in our reference to the model.

\section{The four resources and the digital}

Walther et al. (2011) argue that information reception and processing mechanisms are being influenced by media convergence, nuanced by interpersonal dynamics and motivations. Kress (2003, pp. 166-167) proposes that 'the screen is now the dominant site of texts'. He argues that the reading of a multi-modal text has become more complex and places greater demand on the reader; and that there is a shift towards production, or more appropriately 'interested design'. This means that learning with and about the digital may be correspondingly more complex.

Two key questions for consideration are: how well does a model for literacy translate to the digital domain? And, is a model for read/write literacy for younger pupils applicable to undergraduate and postgraduate provision in the context of the digital?

A cogent critique of the four resources model in terms of its applicability to the digital has been made by Lankshear and Knobel (2004), who argue that multi-modal texts differ in significant ways from traditional print texts. However, they do not abandon the model but propose a redefinition of the roles to encompass concepts such as 'designer', 'mediator', 'bricoleur' and 'jammer'. Our approach has been to expand the interpretation of the original terms rather than change them, precisely for the reasons of provenance and proven acceptability within schools identified above. Acknowledging the problematic elision of roles (Lankshear and Knobel 2004), we have preferenced the term 'resources', emphasising both fluidity and the idea of repertoire. In the following sections, we elaborate some of the commonalities and distinctions between conventional and digital literacy and offer a rearticulation of the four resources as the five resources framework. This elaboration also serves to highlight the level of sophistication and the critical acuity required by both teachers and learners in operating as 'digitally literate' professionals, citizens and individuals. It is this sophistication which confirms the appropriateness of a critical approach at the level of higher education.

\section{The five resources of critical digital literacy}

The resources relate to practice and are indicative of repertoire; there is thus interrelation and overlap between them. The overview below, therefore, is not intended to signal exclusive categorisation or separation. 


\section{Decoding: practical and operational engagement}

Code breaking resources or coding practice involves the ability both to decipher and produce (encode) texts at a practical level. This does not imply being restricted to the physical, however, and includes an understanding of the grammars, functions and structures of texts. Typically cited examples of code breaking relate to the alphabet, phonics, syntax, spelling, punctuation and vocabulary (e.g. Ludwig 2003). These elements do not transfer directly to the digital but they do have their equivalents.

Digital texts often carry within them the conventions of pre-existing textual practice such as a common use or reference to pagination, both deriving from the practicalities of interplay between digital and analogue texts (e.g. printing a document) but also to take advantage of existing conceptual frames of reference as in the use of 'web page', 'file' and 'folder' (Evans 2013). Alongside practices that have been adapted from or developed out of existing ones, there are new and emerging forms reflecting the digital context. 'Texting' involves new forms of vocabulary and grammar as well as new practices relating to time and space (status updates and conversational text, for example). Digital texts are, or have become, predominantly multi-modal (e.g. graphical user interfaces are the norm, context sensitivity is driven by 'spatial' visual cues - i.e. the position of a cursor determines the result of a mouseclick). There are also new operations for creating, navigating and interacting with digital texts, for example 'swiping' or gesture-based and voice controls. Issues of data and identity security, along with possibilities for material corruption of texts, become part of the process of reading and understanding the narratives within these technologies. As a result, the resource learners need for decoding and making meaning from multi-modal texts have an increased scope. This includes new terminology and sign systems; presentational conventions and stylistic options; navigational mechanisms; and operational concepts and protocols such as the distinction between 'save' and 'save as'.

An overview of the decoding resource and its characteristic dimensions is provided in Figure 1.

\section{Meaning making: narrative complexity in the digital}

The text-participating resources (otherwise referred to as 'semantic practice' or by the 'meaning maker' role) are concerned with the reflexive processes underpinning comprehension and composition of texts. It focuses on understanding and interpreting narratives within the content rather than those around authorial standpoints.

Meaning making practices in digital texts are more likely to be multi-modal (Kress 2003). The existing purposes and conventions of digital texts are not always rigidly defined and can be subject to rapid metamorphosis or splintering; reading and creation practices may therefore be similarly fluid.

The spread of the internet across areas of textual practice has meant that hypertextuality and network texts have become common, perhaps the norm. By 'network texts', we mean texts that are compounded of other texts, the component texts being simultaneously available both in their own right and as components of yet further texts. Working on or with such texts requires multiple concurrent levels of meaning making, constructing or interpreting narratives both within the component texts and at the network level. Furthermore, internet and 'Web2.0' practices can create multi-authored, rhizomatically developed texts in which there may not be a 

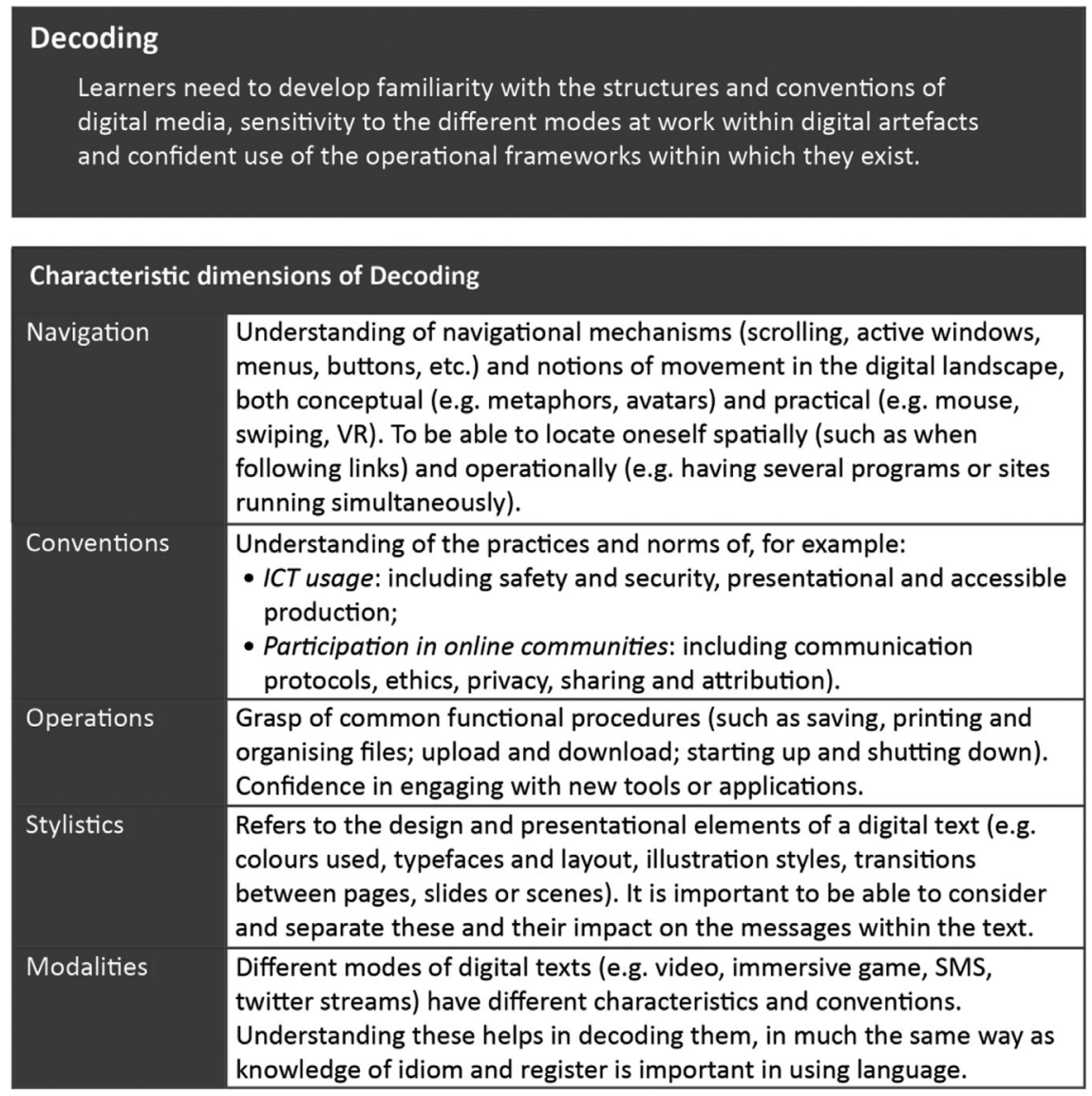

Figure 1. The decoding resource and its characteristic dimensions.

clear, internal consistency to the narratives. Not only may there be conflicting narratives within the same text, but these may fluctuate over time; the text and its narratives become more fluid (Bayne 2006; Pachler and Daly 2009). Given the developing perspectives that the reader may bring on different occasions, this creates a dual fluidity between reader and text and makes it necessary to approach texts with the understanding that this fluidity may be a characteristic of their form; the material of the text and consequently its potential meanings may have changed since the last reading (Kress 2003; Lurie 2003).

Possibly novel requirements in digital contexts are: the application of meaning making practices to online interpersonal interactions; and reading and expressing meaning through participation in communal activities. Interpersonal relationships that have been initiated and are predominantly maintained in a digital environment may exhibit similar characteristics to fictional narratives, leading to a blurred distinction between people and characters in terms of the affective resources brought to bear and to quasi-fictional relationships (Suler 2004). In consequence, it becomes more important to maintain an awareness of the underlying material situation when considering the import and impact of narratives; moral and ethical judgement around tone, voice and context may take on an enlarged role. Such considerations need to be understood by teachers in developing their students' digital literacies. 
An overview of the meaning making resource and its characteristic dimensions is provided in Figure 2.

\section{Using: producing and consuming digital texts}

The text using resources are concerned with the appropriate use of specific text forms for given purposes and involves understanding both the particular characteristics of different texts and the particular requirements of different contexts of use.

A number of practices have shifted from being specialist, often institutionally controlled operations to being within the scope of groups and individuals. Examples are the functions of selection and curation of materials, printing, typing, typesetting and image or video editing. This could be seen both as empowering users, who gain more control over the timescales and nature of their production, but also as burdening them with increased responsibility for its management and an increased range of vocabularies and sign systems of which understanding is expected as normal practice. In the example of typesetting, these practices have also moved from being applied to a text as a secondary process of creation to being much more intimately bound up with the writing process itself (Yancey 2004). Presentational modes such as emphasis (bold, italics, colour) and a variety of fonts are now available within a single operational domain (word-processor or email programme, for example) allowing them to be rapidly applied and removed, for design and layout to be composed simultaneously with the written narrative, leading to a more ad hoc, prototyping process of text production. Thus, design, production and dissemination of digital texts require a wide repertoire of skills and critical evaluation of choices and their implications.

The expansion of available existing texts (a result of increased efficiency and connectivity of digital storage) raises the probability of both encountering and using
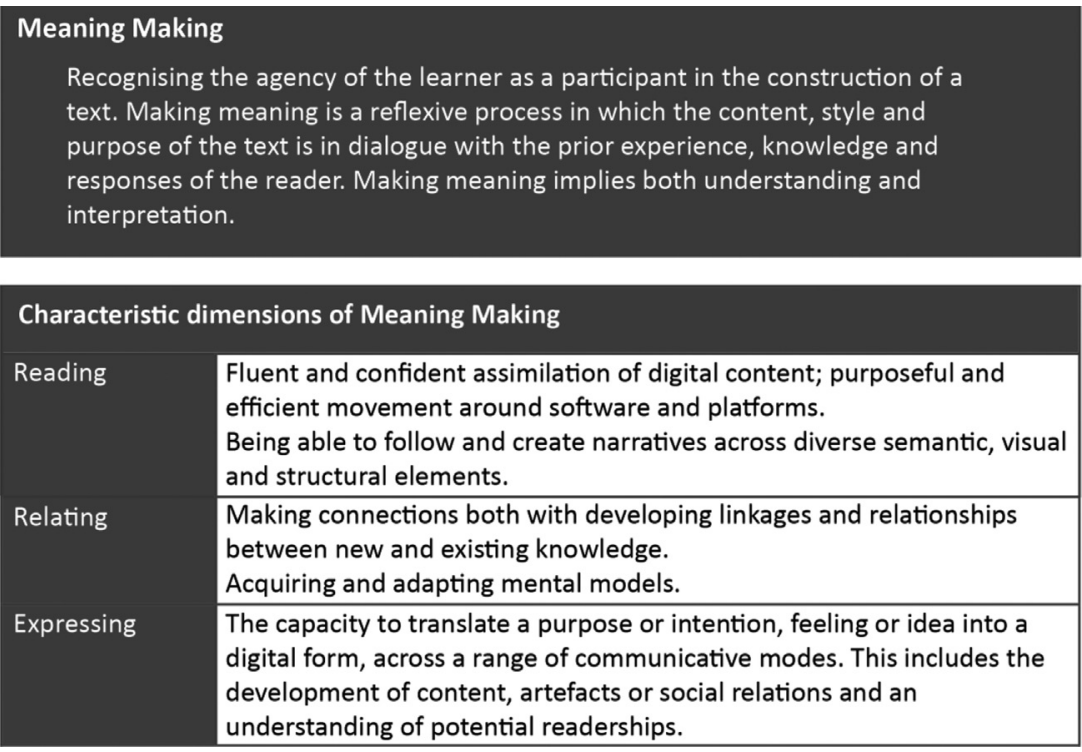

Figure 2. The meaning making resource and its characteristic dimensions. 
direct repurposing, sampling and recombination practices. This increases the value and risks attached to selection, blending and curation. As well as the number of texts, the variety of text forms that require reading and, increasingly, writing have proliferated in recent decades. In addition to more established media modes (written text, static and dynamic images, sound, moving image) there is also the game, the 'twitterverse', the videodiary, the several forms of website; these have their own codes and conventions that impact on how one might understand, engage with or produce them. The vast range of tools (including apps), modalities and forms enable multiple potential solutions to problems but require understanding of their functions, constraints and advantages for effective application. Additionally, the informational scale of the internet, databases and specialist datasets require highly developed search, locationing and query formulation skills.

The novelty and rapid change in the development of digital technologies means that new and unexplored purposes, potentials and problems seem likely to become available at a similarly rapid rate. The existing purposes and conventions of digital texts are not always rigidly defined and can be subject to rapid metamorphosis or splintering; reading and creation practices may therefore be similarly fluid, with individuals contributing to the establishment of conventions through challenge, experimentation and consolidation of practice norms. There are thus both practical and creative aspects to being a text user in digital contexts.

An overview of the using resource and its characteristic dimensions is provided in Figure 3 .

\section{Analysing: becoming a discerning practitioner}

Issues of provenance are complex when authorship is mediated digitally. Bayne (2006) argues that individual authorship is deprivileged by collective forms such as wikis, whilst tools such as RSS feeds, and the potential of anonymity (e.g. in chat
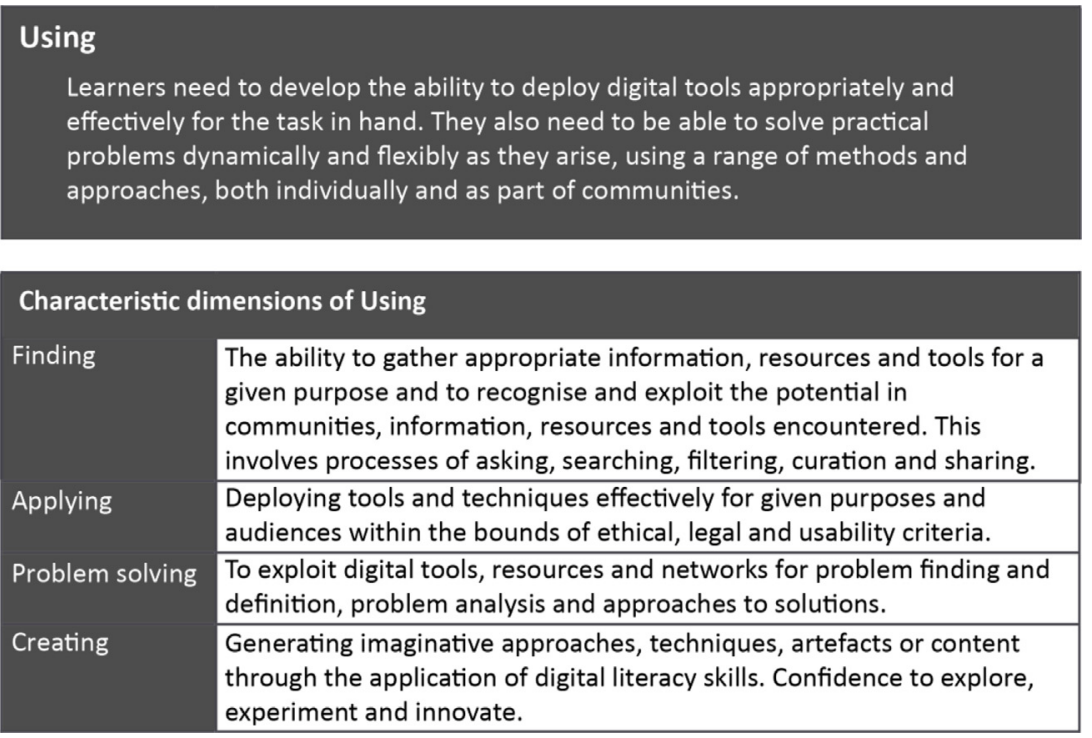

Figure 3. The using resource and its characteristic dimensions. 
rooms, online 'handles' or avatars) all serve to distance the author/s from the text/s. Critical evaluation becomes central in these contexts and learners may require the decoding skills referred to previously to trace and track provenance. They will also need to discern the ideology inherent in a source (Buckingham 2006). The submerging of qualitative and quantitative methods underlying aggregated or processed data (including search engines, ratings, databases) may need to be exposed, for example. Developments such as 'liking' and 'trending' offer new propositions in relation both to the form and quality of evidence they present. Many developments in digital technologies are perceived in terms of challenges to traditional academic value hierarchies (Bayne 2006) and learners will need to develop their own values as researchers in this context.

The increase in access to publishing opportunities accompanying the development of the worldwide web means that individuals may be more directly and personally confronted with legal, ethical and moral decision making in relation to how, where and to whom they should publish. This requires a careful reading of the systems and processes available to them, both technical and social. For example, since personal profiles and online identities function as texts, we may now be dealing much more with consequences relating to self-image and public standing (Aula 2010).

An overview of the analysing resource and its characteristic dimensions is provided in Figure 4.

\section{Persona: identity issues and the digital}

One of the challenges presented by new technologies, and social media in particular, lies in the presentation of self. The disembodiment of virtual spaces can render a decontextualised identity whilst, paradoxically, choice in presentation, locality and juxtaposition act to recontextualise, and hence change, that identity. The extent to which that presentation is managed (e.g. in terms of language, image, content) and control over those choices is exerted (e.g. privacy settings, placement, disclaimers) are new skillsets. The multiple potential audiences of friends, colleagues, employers, clients or markets and the variation of profile which may therefore be required necessitates understanding of how to manage both the varied, disaggregated texts
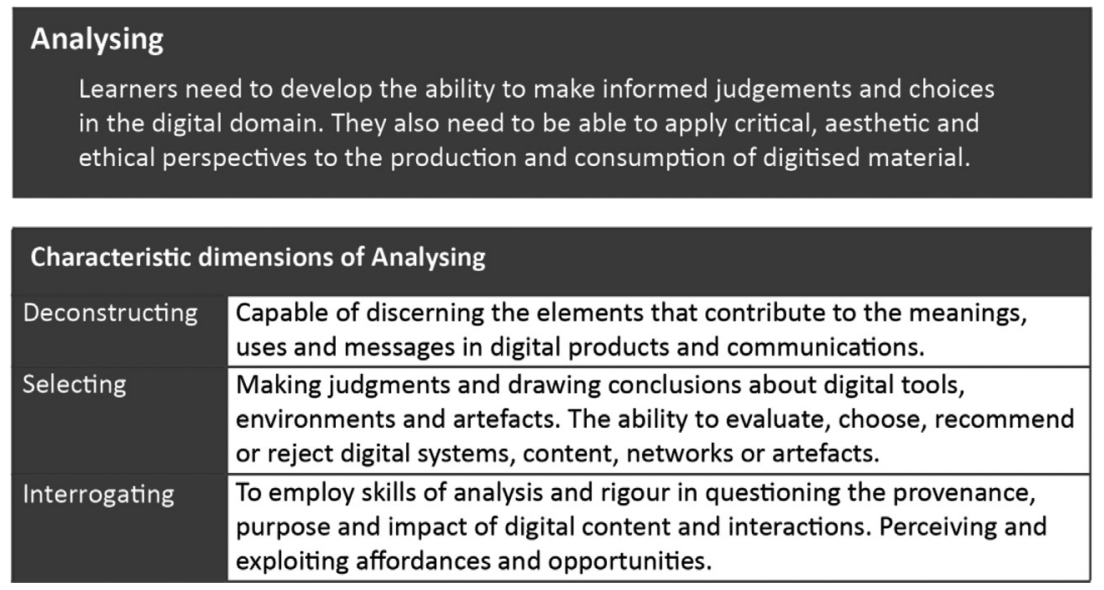

Figure 4. The analysing resource and its characteristic dimensions. 
which may go to form such profiles, and the characteristics and security features of the environments in which they may operate ('impression management', boyd and Ellison 2007). These aspects are qualitatively different from traditional texts; although more present in conventional media it has not generally been the case that a majority of students would need educational support to manage self-presentation on radio or television; nor would proliferation and potential alteration be so rapid and possibly uncontrollable. The multiplicity of avenues to publicity ['masspersonal messages' (Walther et al. 2011, p. 34)] and the varied and globalised communication channels such as formal discussion groups, personal blogs, microblogs, videologs, and so on also requires choice and judgement about how, where and when to participate and for what purposes. These factors have a prominence in the digital which is not reflected in the four resources model. One may debate the inclusion of these practices within the scope of literacy; however, as they cannot be disengaged from the practices of reading and writing in and for the digital environment, and since participation is mediated by multi-modal textual forms, we consider them to be key in characterising digital literacy. A fifth resource, persona, was therefore introduced to take account of this.

The lack of transference between academic and personal or social practices by learners, noted earlier, is of more concern when one considers the elision of these domains in the digital. Reputation, image projection and interpersonal relations are both mediated by and become repositories in the digital. This has lasting impact on professional profile, both positively and negatively (note the rise of 'digital forgetting' consultancies). Development and management of one's online persona/e can be considered both a professional and a graduate attribute but can only be effectively developed in conjunction with the other literacy resources.

An overview of the persona resource and its characteristic dimensions is provided in Figure 5.
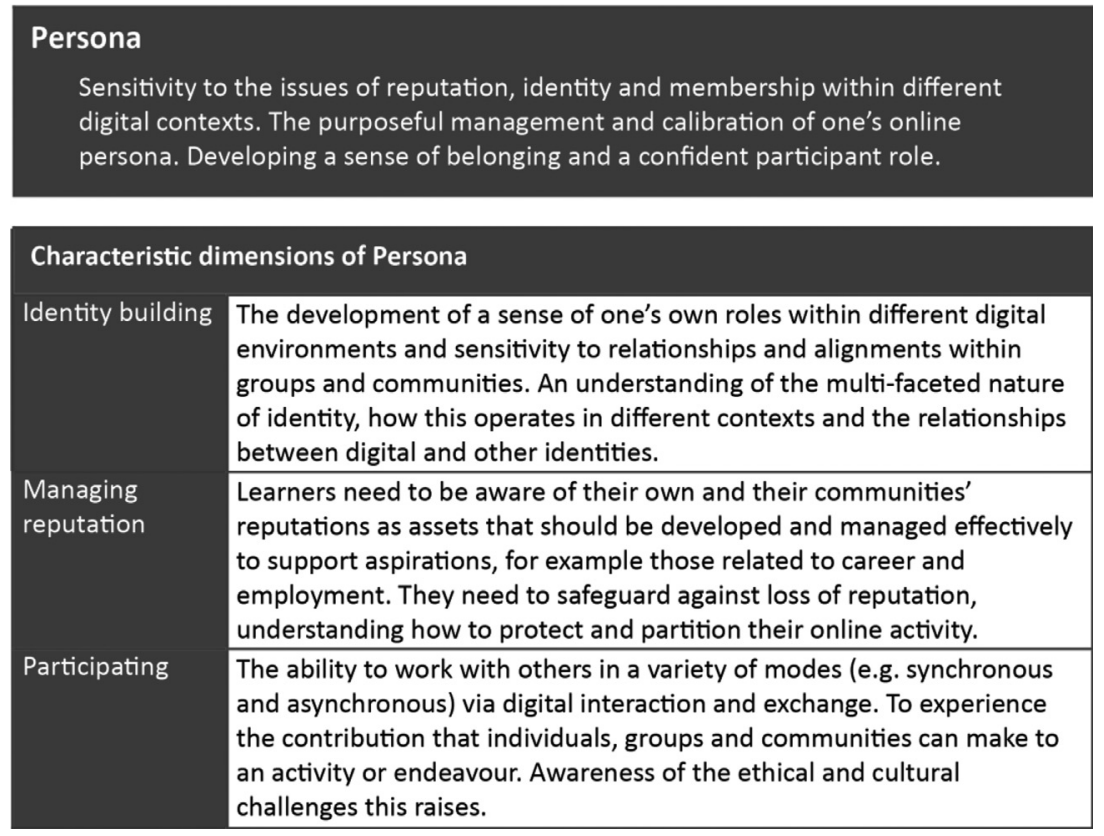

Figure 5. The persona resource and its characteristic dimensions. 


\section{Elaborating the resources with characterising dimensions}

The four resources model articulates each resource at a conceptual level based on 'families of practice' but does not detail specific competencies. These are seen to be areas for interpretation and management by the teacher. Whilst we share the goal of maintaining teacher autonomy, we were aware of a significant difference in context regarding digital literacy: teachers can be considered expert practitioners in reading and writing, in literacy, and are more skilled than their pupils in this domain. Conversely, many academics may not identify themselves as expert in the use of computers, particularly at the level and range being considered, whilst their students will vary in expertise as highlighted previously. Additionally, terms such as 'meaning making' may lack appropriate significance for individuals where this is not a theoretical construct as it is in literacy/literary and media domains. Finally, whilst wishing to avoid specification of a curriculum, our project was to develop staff practices and curriculum application in ways that would help to support and scope digital literacy development in practical contexts. It was therefore necessary to articulate some dimensions to the resource categories in order to provide conceptual delineation and to concretise avenues of application, whilst maintaining consistency with the original model. These component dimensions were arrived at through a process of testing the original four resources against the digital, identifying equivalence and working through example applications and contexts.

\section{Discussion}

There are some interesting implications in problematising the epistemological paradigms underlying concepts of 'digital literacy'. One of these is the potential reconstitution of the profile of a 'digitally literate' person. Where would the critically astute but technically limited be regarded on a maturity scale in relation to the technically competent but critically naive, for example? What should humanities be teaching learning technologists? In other words, what implications are there for the notion of expertise when we think about digital literacy, how it should be taught and developed and by whom?

In curriculum terms, the development of digital literacy will involve using devices and software but should also be recognised and made explicit in analytical and discursive practices; in syllabus content; in assessment design and grading criteria; and in formal course specification documents, having implications for validation panel training and membership. Strategic integration at institutional and departmental levels becomes vital, as does the alignment with employer and professional discourses, demands and requirements. As the notion of critical literacy is highly consonant with the concept of academic literacies, such curriculum issues can be approached through the existing expressions of this: graduate attributes, subject benchmarks and programme aims repeatedly articulate critical, evaluative and scholarly outcomes.

A final, more philosophical, question is raised by the complex relations of individual and collective practices and identity elaborated previously. Can a group, community of practice or institution be 'digitally literate'? What does that mean? How would it be recognised? Such questions may have important practical consequences and need further elaboration and exploration. 


\section{Acknowledgements}

The authors thank Simon Walker and Mark Kerrigan, University of Greenwich, for their practical support and dialogue. This work arises from a JISC-funded project, Digital Literacies in Transition. (http://www.jisc.ac.uk/whatwedo/programmes/elearning/developingdigitalliteracies/ DLinTransition)

\section{References}

Aula, P. (2010) 'Social media, reputation risk and ambient publicity management', Strategy \& Leadership, vol. 38, no. 6, pp. 43-49.

Balamurugan, S. A. A. et al. (2008) 'Classification methods in the detection of new suspicious emails', Journal of Information \& Knowledge Management, vol. 7, no. 3, pp. 209-217.

Barton, E. L. (1994) 'Interpreting the discourses of technology', in Literacy and Computers: The Complications of Teaching and Learning with Technology, eds C. L. Selfe \& S. Hilligoss, The Modern Langauage Association of America, New York, pp. 56-75.

Bayne, S. (2006) 'Temptation, trash and trust: the authorship and authority of digital texts', E-Learning and Digital Media, vol. 3, no. 1, pp. 16-26.

Bayne, S. \& Ross, J. (2007) 'The 'digital native' and 'digital immigrant': a dangerous opposition', Annual Conference of the Society for Research into Higher Education (SRHE) 20 December 2007, Brighton.

Bennett, S., Maton, K. \& Kervin, L. (2008) 'The 'digital natives' debate: a critical review of the evidence', British Journal of Educational Technology, vol. 39, no. 5, pp. 775-786.

Beynon, J. \& Mackay, H. (eds) (1992) Technological Literacy and the Curriculum, The Falmer Press, London.

boyd, d. m. \& Ellison, N. B. (2007) 'Social network sites: definition, history, and scholarship', Journal of Computer-Mediated Communication, vol. 13, no. 1. Available at: http:// jcmc.indiana.edu/vol13/issue1/boyd.ellison.html

Buckingham, D. (2006) 'Defining digital literacy - What do young people need to know about digital media?', Nordic Journal of Digital Literacy, 2006, no. 4, pp. 263-276.

Cockburn, C. (1985) Machinery of Dominance: Women, Men and Technical Know-How, Pluto Press, London.

Cockburn, C. (1991) 'The gendering of technology', in Understanding Technology in Education, eds H. Mackay, M. F. D. Young \& J. Beynon, The Falmer Press, London, pp. 41-65.

Dowling, P. (1991) 'A dialectics of determinism: deconstructing information technology', in Understanding Technology in Education, eds H. Mackay, M. F. D. Young \& J. Beynon, The Falmer Press, London, pp. 176-192.

Evans, C. (2013) 'A eulogy for skeuomorphism', Motherboardl. Available at: http:// motherboard.vice.com/read/a-eulogy-for-skeumorphism

Freebody, P. (2002) 'A socio-cultural approach: resourcing four roles as a literacy learner', MyRead. Available at: http://www.myread.org/readings_freebody.htm

Freebody, P. \& Luke, A. (1990) 'Literacies programs: debates and demands in cultural context', Prospect: An Australian Journal of TESOL, vol. 5, no. 3, pp. 7-16.

Glastonbury, B. \& LaMendola, W. (1992) The Integrity of Intelligence: A Bill of Rights for the Information Age, Macmillan, Basingstoke.

Goodfellow, R. (2011) 'Literacy, literacies and the digital in higher education', Teaching in Higher Education, vol. 16, no. 1, pp. 131-144.

Haddon, L. (1991) 'The cultural production and consumption of IT', in Understanding Technology in Education, eds H. Mackay, M. F. D. Young \& J. Beynon, The Falmer Press, London, pp. 157-175.

Henderson, R. \& Hirst, E. (2007) 'Reframing academic literacy: re-examining a short-course for 'disadvantaged' tertiary students', English Teaching: Practice and Critique, vol. 6, no. 2, pp. 25-38.

Hirst, E. et al. (2004) 'Repositioning academic literacy: charting the emergence of a community of practice', Australian Journal of Language and Literacy, vol. 27, no. 1, pp. 66-80.

Honan, E. (2008) 'Barriers to teachers using digital texts in literacy classrooms', Literacy, vol. 42 , no. 1 , pp. $36-43$.

Jones, C. et al. (2010) 'Net generation or digital natives: is there a distinct new generation entering university?', Computers \& Education, vol. 54, no. 3, pp. 722-732. 
Jones, C. (2011) 'Students, the net generation, and digital natives - accounting for educational change', in Deconstructing Digital Natives: Young People, Technology, and the New Literacies, ed M. Thomas, Oxon, Routledge, pp. 30-48.

Kahn, R. \& Kellner, D. (2005) 'Reconstructing technoliteracy: a multiple literacies approach', E-Learning and Digital Media, vol. 2, no. 3, pp. 238-251.

Kennedy, G. E. \& Judd, T. S. (2011) 'Beyond Google and the 'satisficing' searching of digital natives', in Deconstructing Digital Natives: Young People, Technology, and the New Literacies, ed M. Thomas, Routledge, Oxon, pp. 119-135.

Kress, G. (2003) Literacy in the New Media Age, Routledge, Oxon.

Lankshear, C. \& Knobel, M. (2004) 'Text-related roles of the digitally 'at home", in American Education Research Assciation Annual Meeting, San Diego. Available at: http:// everydayliteracies.net/files/roles.html

Lea, M. R. (2013) 'Reclaiming literacies: competing textual practices in a digital higher education', Teaching in Higher Education, vol. 18, no. 1, pp. 106-118.

Lea, M. R. \& Goodfellow, R. (2009) 'Academic literacies in the digital university', in Literacy in the Digital University: The Relation of New Media Practices to Traditional Literacy Practices in the Academy and the Professions, Edinburgh University, Edinburgh. 16 October.

Levy, M. \& Michael, R. (2011) 'Analyzing students' multimodal texts: the product and the process', in Deconstructing Digital Natives: Young People, Technology, and the New Literacies, ed M. Thomas, Routledge, Oxon, pp. 83-98.

Littlejohn, A., Beetham, H. \& McGill, L. (2012) 'Learning at the digital frontier: a review of digital literacies in theory and practice', Journal of Computer Assisted Learning, vol. 28, no. 6 , pp. 547-556.

Livingstone, S. (2004) 'Media literacy and the challenge of new information and communication technologies', Communication Review, vol. 1, no. 7, pp. 3-14.

Ludwig, C. (2003) 'Making sense of literacy', ALEA Today, February. Available at: http:// www.alea.edu.au/documents/item/53

Luke, A. \& Freebody, P. (1999) Further Notes on the Four Resources Model. Available at: http:// www.readingonline.org/research/lukefreebody.html

Lurie, P. (2003) 'Why the web will win the culture wars for the left: deconstructing hyperlinks', $C$ Theory, [Online] Available at: http://www.ctheory.net/articles.aspx?id=380

Lyon, D. (1994) The Electronic Eye: The Rise of Surveillance Society, Polity Press, Cambridge.

Mackay, H., Young, M. F. D. \& Beynon, J., (eds) (1991) Understanding Technology in Education, The Falmer Press, London.

Mackenzie, D. \& Wajcman, J., (eds) (1985) The Social Shaping of Technology, Open University Press, Buckingham.

Margaryan, A., Littlejohn, A. \& Vojt, G. (2011) 'Are digital natives a myth or reality? University students' use of digital technologies', Computers \& Education, vol. 56, no. 2, pp. 429-440.

Mendelson, A. L. \& Papacharissi, Z. (2011) 'Look at us: collective narcissism in college student faceBook photo galleries', in A. Networked Self, ed. Z. Papacharissi, Oxon, Routledge, pp. 251-273.

Pachler, N. \& Daly, C. (2009) 'Narrative and learning with Web 2.0 technologies: towards a research agenda', Journal of Computer Assisted Learning, vol. 25, no. 1, pp. 6-18.

Payton, S. (2012) JISC Briefing: Developing Digital Literacies, Bristol. Available at: http:// www.jisc.ac.uk/media/documents/publications/briefingpaper/2012/Developing_Digital_ Literacies.pdf

Pearce, N., et al. (2010) 'Digital scholarship considered: how new technologies could transform academic work', In Education, vol. 16, no. 1. Available at: http://ineducation. ca/article/digital-scholarship-considered-how-new-technologies-could-transform-academicwork

Prensky, M. (2001) 'Digital natives, digital immigrants', On the Horizon, vol. 9, no. 5, pp. 1-6.

Selfe, C. \& Hilligoss, S., (eds) (1994) Literacy and Computers: the Complications of Teaching and Learning with Technology, The Modern Language Association of America, New York.

Street, B. (2003) 'What's 'new' in new literacy studies? critical approaches to literacy in theory and practice', Current Issues in Comparative Education, vol. 5, no. 2, pp. 77-91. 
Suler, J. (2004) 'The online disinhibition effect', Cyberpsychology \& Behavior, vol. 7, no. 3, pp. $321-326$.

The Literacy and Numeracy Secretariat (Ontario Ministry of Education) (2009) Capacity Building Series: Critical Literacy (Special Edition no. 9), 8482(August).

Tweed, P. (2012) 'Lord McAlpine and the high cost of tweeting gossip', The Guardian, 27 Nov., [Online]. Available at: http://www.guardian.co.uk/law/2012/nov/27/lord-mcalpine-twitterlibel

Wahlstrom, B. J. (1994) 'Communication and technology: defining a feminist presence in research and practice', in Literacy and Computers: The Complications of Teaching and Learning with Technology, eds C. Selfe \& S. Hilligoss, The Modern Langauage Association of America, New York, pp. 171-185.

Walther, J. B. et al. (2011) 'Interaction of interpersonal, peer and media influence sources online: a research agenda for technology convergence', in A Networked Self, ed Z. Papacharissi, Routledge, Oxon, pp. 17-38.

Yancey, K. B. (2004) 'Using multiple technologies to teach writing', Educational Leadership, vol. 62 , no. 2 , pp. $38-40$.

Yorke, M. (2006) Employability in Higher Education: What It Is - What It Is Not, Higher Education Academy, York. 